\title{
PENGGUNAAN METILPREDNISOLON SEBAGAI PEREDA NYERI PADA PASIEN NYERI PUNGGUNG BAWAH AKUT RAWAT JALAN RUMAH SAKIT BETHESDA YOGYAKARTA
}

\author{
Tiara Triasari ${ }^{1}$, Rizaldy Taslim Pinzon ${ }^{2}$ \\ ${ }_{1}^{1}$ Fakultas Farmasi Universitas Sanata Dharma \\ 2 Fakultas Kedokteran Universitas Kristen Duta Wacana
}

Korespondensi: tiaratriasari@gmail.com

\begin{abstract}
ABSTRAK
Nyeri punggung bawah (NPB) akut merupakan penyakit umum dan penyebab keterbatasan dalam bekerja maupun melakukan aktivitas sehari-hari yang terjadi selama kurang dari 12 minggu atau terjadi selama 6 bulan dengan interval tanpa nyeri. Pada penelitian sebelumnya dilaporkan bahwa penambahan metilprednisolon untuk terapi NPB tidak memberikan hasil yang baik bila dibandingkan dengan tanpa metilprednisolon. Mengukur penurunan nilai VAS serta mengidentifikasi outcome dan efek samping aktual yang terjadi pada penambahan metilprednisolon pada pasien NPB akut di instalasi rawat jalan rumah sakit Bethesda Yogyakarta. Observasional-analitik dengan rancangan kohort. Subjek penelitian pada penelitian ini adalah pasien NPB akut yang dikelompokkan berdasarkan jenis terapi yang diterima yaitu kelompok analgesik nonsteroid dengan atau tanpa tambahan metilprednisolon $4 \mathrm{mg}$. Data diukur dengan VAS (Visual Analog Scale), dan diidentifikasi dengan kuisioner subjektif dan obyektif. Diperoleh 30 NPB akut yang terdiri dari 11 pasien laki-laki (36,67\%) dan 19 pasien perempuan (63,33\%) dengan $40 \%$ pasien berusia $>62$ tahun, 46,67\% 41-62 tahun, dan 13,33\% pasien berusia 18-41 tahun. Sebanyak 15 pasien masuk dalam kelompok terapi NPB akut tanpa metilprednisolon dan 15 pasien masuk dalam kelompok dengan tambahan metilprednisolon $4 \mathrm{mg}$ untuk terapi NPB akut. Hasil analisis penambahan metilprednisolon $4 \mathrm{mg}$ terhadap pengurangan nyeri tidak terdapat perbedaan bermakna pada rata-rata penurunan nilai VAS sebelum dan setelah terapi $(p=0,253)$, outcome terapi berupa pengurangan nyeri saat beraktivitas $(p=0,589)$ dan menjelang atau saat tidur $(\mathrm{p}=0,330)$, efek samping aktual pada kedua kelompok, dan rata-rata selisih nilai VAS pada tiga kelompok berdasarkan regimen dosis metilprednisolon tidak berbeda bermakna $(p=0,792)$. Penambahan metilprednisolon untuk terapi NPB akut dapat menurunkan nilai intensitas nyeri, tercapainya outcome terapi, dan tidak terdapat perbedaan efek aktual namun tidak berbeda bermakna dengan terapi NPB akut tanpa metilprednisolon.
\end{abstract}

Kata kunci: Nyeri Punggung Bawah, Metilprednisolon 


\title{
THE USE OF METHYLPREDNISOLONE AS A PAIN RELIEVER IN ACUTE LOW BACK PAIN PATIENTS AT AMBULATORY DEPARTMENT BETHESDA HOSPITAL YOGYAKARTA
}

\author{
Tiara Triasari ${ }^{1}$, Rizaldy Taslim Pinzon ${ }^{2}$ \\ 1 Faculty of Pharmacy Sanata Dharma University \\ 2Medical School of Duta Wacana Christian University \\ Correspondence: tiaratriasari@gmail.com
}

\begin{abstract}
Acute low back pain (LBP) is a pain commonly known as the major cause of working and daily activities limitation that happened in less than 12 weeks or it happened in 6 months with intervals without pains. In previous researches the results of the use of methylprednisolone didn't give any better results in reducing low back pain compared to reducing low back pain without methylprednisolone. To measure the reducing of VAS score, and to identify therapy outcomes and actual side effects of acute low back pain patients in ambulatory department of Bethesda Hospital Yogyakarta. Observational-analytic with cohort design. Subjects of this research are acute low back pain patients that were divided into two groups based on addition of methylprednisolone $4 \mathrm{mg}$ in acute low back pain therapy. Data measured with VAS (Visual Analog Scale) and identified with subjective and objective questionnaire. Tthere were 11 male patients $(36,67 \%)$ and 19 female patients $(63,33 \%)$ with $40 \%$ of them are on age $>62$ years old, 46,67\% are 41-62 years old and 13,33\% are 18-40 years old. Fifteen patients are in analgetic alone group and 15 patients are in analgetic with addition of methylprednisolon $4 \mathrm{mg}$ for acute low back pain therapy group. Results of the addition of methylprednisolone for pain reducing analysis not significantly different on the average of VAS scores before and after taking methylprednisolone $(p=0,253)$, the therapy outcomes on reducing pain while doing an activity $(p=0,589)$ and reducing pain before or at sleep time ( $p=0,330)$, the side effects between two groups, and the average of VAS score differences between the three groups that were divided based on the dose regimen of Methylprednisolone $(p=0,792)$ compared to the analgetic alone group in low back pain therapy. The use of methylprednisolone for acute low back pain reduced the average of pain intensities before and after therapy, achieved the therapy outcomes, and there were no differences in side effects but the statistically not significant different compared to the analgetic alone group in low back pain therapy.
\end{abstract}

Keywords: Low Back Pain, Corticosteroid, Methylprednisolone 


\section{PENDAHULUAN}

Nyeri Punggung Bawah (NPB) atau Low Back Pain (LBP) merupakan penyakit umum dan penyebab keterbatasan dalam bekerja maupun melakukan aktivitas sehari-hari. Nyeri punggung bawah (NPB) adalah penyakit yang dapat menurunkan produktivitas penderitanya. ${ }^{1}$ Angka kejadian NPB adalah 1 diantara 4 dewasa mengalami NPB dalam 1 hari selama rentang waktu 3 bulan atau mereka mengalami NPB sekali seumur hidupnya. ${ }^{2}$ Nyeri punggung bawah yang terjadi selama kurang dari 12 minggu atau kurang dari 3 bulan maka nyeri punggung tersebut masuk dalam nyeri punggung akut. Nyeri punggung akut juga merupakan nyeri yang berulang selama 6 bulan dengan adanya interval tanpa nyeri. ${ }^{3}$ Populasi lanjut usia ataupun populasi produktif mempunyai faktor risiko untuk mengalami NPB. ${ }^{4}$ Nyeri punggung bawah dapat disebabkan oleh bermacam hal seperti kelainan pada bagian tulang belakang, kelainan kongenital, trauma minor, fraktur, herniasis diskus intervertebralis, degeneratif, arthritis, tumor pada tulang primer, kelainan vaskular dan sikap tubuh. ${ }^{5}$

Obat-obat yang digunakan untuk mengobati NPB adalah golongan anti inflamasi, opiod, paracetamol dan muscle relaxant. Anti inflamasi yang diberikan terdapat dua golongan yaitu obat anti inflamasi non steroid (OAINS) atau non steroid anti inflamatory drugs (NSAID) dan steroid. ${ }^{3}$ Kortikosteroid merupakan golongan hormon steroid yang sangat penting yang berefek pada fisiologi manusia. Mekanisme aksi kortikosteroid sebagai anti inflamasi adalah dengan menghambat sintesis asam arakidonat oleh pospolipid agar tidak membentuk prostaglandin dan leukotrien untuk mengeluarkan mediator inflamasi serta menurukan permeabilitas vaskular pada daerah yang mengalami inflamasi. ${ }^{6}$

Metilprednisolon

diindikasikan untuk penekanan inflamasi dan kelainan hipersensitivitas, inflamasi bowel parah, edema serebral disertai dengan keganasan, rematik, dan inflamasi kulit. Dosis metil-prednisolon untuk indikasi tersebut adalah 2-40 $\mathrm{mg} /$ hari secara peroral, sedangkan dosis dengan pemberian secara intramuskular, intravena lambat atau infus adalah $10-500 \mathrm{mg} /$ hari. $^{7}$ Metilprednisolon mem-punyai waktu paruh 18-36 jam dan dapat mencapai kadar plasma puncak (Cp max) dalam waktu minimal 1,1-2,2 jam. ${ }^{8}$

Menurut Finckh, penggunaan steroid pada pasien yang terdiagnosa sciatica efek terapi steroid tidak berlangsung lama dan efek tidak teratur dalam beberapa hari. ${ }^{9}$ Pada penelitian yang dilakukan Friedman, et al, tentang penggunaan metilprednisolon pada pasien NPB menunjukkan hasil bahwa pada kelompok plasebo dengan tambahan metilprednisolon mengalami perbaikan nilai nyeri dibanding kelompok kontrol stelah dilakukan terapi selama 1 bulan. Meskipun rata-rata nilai intensitas nyeri pada kelompok plasebo dengan tambahan metilprednisolon lebih baik, namun uji statistik untuk intensitas nyeri diperoleh $\quad \mathrm{p}=0,10 \quad$ (selang kepercayaan: 95\%). Hasil penelitian yang menunjukkan bahwa penggunaan steroid berbeda tidak bermakna dibandingkan dengan kelompok kontrol mendukung tidak digunakannya steroid sebagai terapi NPB di beberapa guideline. ${ }^{2}$

\section{TUJUAN}

Tujuan dari penelitian ini untuk mengukur efek metilprednisolon dalam menurukan nyeri pada pasien NPB akut dan untuk mengetahui efek samping dari 
penggunaan metilprednisolon pada pasien NPB akut di instalasi rawat jalan rumah sakit Bethesda Yogyakarta.

\section{METODE PENELITIAN}

\section{Rancangan Penelitian}

Jenis penelitian adalah observasional-analitik dengan racangan kohort. Dalam penelitian ini variabel bebas dibagi menajdi 2 kelompok yaitu kelompok terapi analgesik nonsteroid dan kelompok terapi analgesik nonsteroid dengan tambahan metilprednisolon. Kelompok analgesik nonsteroid dengan metilprednisolon dibagi menjadi 2 kelompok berdasarkan regimen dosis pemberian metilprednisolon yaitu metilprednisolon $4 \mathrm{mg} 2 \mathrm{x}$ /hari dan metilprednisolon $4 \mathrm{mg} 1 \mathrm{x} /$ hari. Variabel terikat adalah nilai VAS setelah terapi diberikan dan efek samping aktual pada pasien NPB akut di instalasi rawat jalan di rumah sakit Bethesda Yogyakarta.

\section{Subjek Penelitian}

Subjek penelitian ini adalah pasien NPB akut dan menerima metilprednisolon di instalasi rawat jalan di rumah sakit Bethesda Yogyakarta yang belum pernah mendapat terapi dengan metilprednisolon atau pasien yang menerima metilprednisolon sebelumnya namun tidak melanjutkan terapi minimal 1 minggu. Kriteria inklusi meliputi pasien dengan jenis kelamin laki-laki maupun perempuan, usia $>18$ tahun, dan telah terdiagnosis NPB akut, pasien menerima metilprednisolon untuk terapi farmakologi NPB akut untuk pertama kalinya atau baru menerima metilprednisolon setelah menghentikan terapi minimal selama 1 minggu. Kriteria eksklusi adalah pasien dengan data rekam medik tidak lengkap, tidak dapat difollow-up selama penelitian, tidak menyetujui informed consent dan pasien telah rutin melakukan terapi dengan metilprednisolon untuk penyakit lain. Besar sampel minimal yang diperloeh dengan meng-gunakan rumus adalah 11 .

Perhitungan besar sampel minimal menggunakan proporsi (p) $15,6 \%$ berdasarkan penelitian Rumawas dan Purba, dengan presisi (e) yang diasumsikan peneliti sebesar 5\% kesalahan yang dapat diterima dalam penelitian. ${ }^{10}$ Penelitian ini diambil 30 pasien NPB yang sesuai kriteria inklusi dan dibagi menjadi dalam 2 kelompok besar berdasarkan terapi dimana masing-masing kelompok terdapat 15 subjek penelitian.

Tabel 1. Deskripsi subjek Penelitian

\begin{tabular}{lcc}
\multicolumn{1}{c}{ Karakteristik } & \multicolumn{2}{c}{ Responden } \\
\cline { 2 - 3 } & n & \% \\
\hline $\begin{array}{l}\text { Jenis kelamin } \\
\text { - Laki-laki }\end{array}$ & 11 & 36,67 \\
- Perempuan & 19 & 63,33 \\
Usia & & \\
- $18-40$ tahun & 4 & 13,33 \\
- 41-62 tahun & 14 & 46,67 \\
- >62 tahun & 12 & 40,00 \\
$\begin{array}{l}\text { Terapi } \\
\text { - Analgesik nonsteroid (kelompok 1) }\end{array}$ & & \\
- Analgesik nonsteroid + & 15 & 50,00 \\
$\quad$ metilprednisolon 4mg 1x/hari & & \\
$\quad$ (kelompok 2) & & \\
\hline
\end{tabular}




\begin{tabular}{|c|c|c|}
\hline \multirow{2}{*}{ Karakteristik } & \multicolumn{2}{|c|}{ Responden } \\
\hline & $\mathbf{n}$ & $\%$ \\
\hline $\begin{array}{l}\text { Analgesik nonsteroid }+ \\
\text { metilprednisolon } 4 \mathrm{mg} 2 \mathrm{x} / \text { hari } \\
\text { (kelompok 3) }\end{array}$ & 8 & 26,67 \\
\hline
\end{tabular}

\section{Bahan dan Instrumen Penelitian}

Bahan penelitian ini adalah catatan dalam rekam medis elektronik (Electronic Medical Record) di poliklinik saraf instalasi rawat jalan rumah sakit Bethesda Yogyakarta yang berisi data subjektif dan obyektif pasien yang diisi oleh dokter, electronic prescription, dan data kunjungan pasien. Instrumen dalam penelitian ini adalah lembar VAS (Visual Analog Scale), lembar data obyektif pasien dan kuisioner terkait outcome terapi dan efek samping aktual yang dialami pasien setelah menjalani terapi.

\section{Persiapan Penelitian}

Ethical clearance untuk penelitian dikeluarkan oleh komisi etik penelitian Fakultas Kedokteran Universitas Kristen Duta Wacana Yogyakarta dan surat izin penelitian dikeluarkan oleh rumah sakit Bethesda Yogyakarta. Disiapkan lembar informed concent sebagai bukti kesediaan responden untuk terlibat dalam penelitian.

\section{Pengambilan dan Analisis Data}

Pengambilan data dilakukan dengan mengukur nilai VAS pada pasien NPB pada saat belum menerima terapi dan 3-14 hari setelah menjalankan terapi, pengisian kuisioner outcome dan kejadian efek samping, dan pengisian data obyektif pasien terkait terapi. Pengukuran nilai VAS digunakan untuk mengukur nilai nyeri sebelum dan sesudah terapi NPB. Pengisian kuisioner digunakan untuk menghitung persentase angka kejadian efek samping dan outcome terapi. Data obyektif digunakan untuk memperoleh data terkait riwayat penyakit, pengobatan yang diterima melalui electronic prescription, dan data pendukung yang tidak dapat diambil langsung dari pasien.

Data dianalisis univariat untuk melihat karakteristik subjek penelitian. Kemudian dilakukan analisis bivariat untuk mengetahui hubungan antara jenis terapi dan regimen dosis terhadap penurunan nilai VAS, outcome dan efek samping aktual. Nilai VAS sebelum dan sesudah terapi pada masing-masing kelompok diuji dengan uji Wilcoxon signed rank. Selisih nilai VAS pada kelompok besar dianalisis dengan uji Mann-Whitney $U$ dan selisih nilai VAS pada kelompok kecil (analgesik nonsteroid, analgesik nonsteroid + metilprednisolon $4 \mathrm{mg} 1 \mathrm{x} /$ hari, dan analgesik nonsteroid + metilprednisolon $4 \mathrm{mg} 2 \mathrm{x}$ /hari) dianalisis dengan uji Kruskal-Wallis. Data nominal dianalisis dengan uji Fisher's Exact. Semua uji statististik dilakukan dengan perangkat lunak SPSS versi 22 lisensi Universitas Gajah Mada Yogyakarta.

\section{HASIL}

\section{Karakteristik Subjek Penelitian}

Subjek penelitian ini adalah 30 pasien NPB akut di poliklinik saraf Rumah Sakit Bethesda Yogyakarta yang memenuhi kriteria inklusi yang terdiri dari 11 pasien laki-laki dan 19 pasien perempuan. Subjek penelitian dibagi menjadi 2 kelompok berdasarkan terapi yang diterima yaitu kelompok analgesik nonsteroid (kelompok 1) dan kelompok analgesik nonsteroid dengan tambahan 
Metilprednisolon $4 \mathrm{mg}$ (kelompok 2). Rentang umur pada kelompok analgesik tanpa metilprednisolon adalah 29-83 tahun dengan rata-rata umur pasien adalah $59,0 \pm 15,26$ tahun. Rentang umur pada kelompok
2 adalah 40-75 tahun dengan ratarata umur pasien adalah $57,67 \pm 10,33$ tahun. Rata-rata umur pada kedua kelompok berbeda tidak bermakna $(p=0,819)$.

Tabel 2. Karakteristik Subjek Penelitian

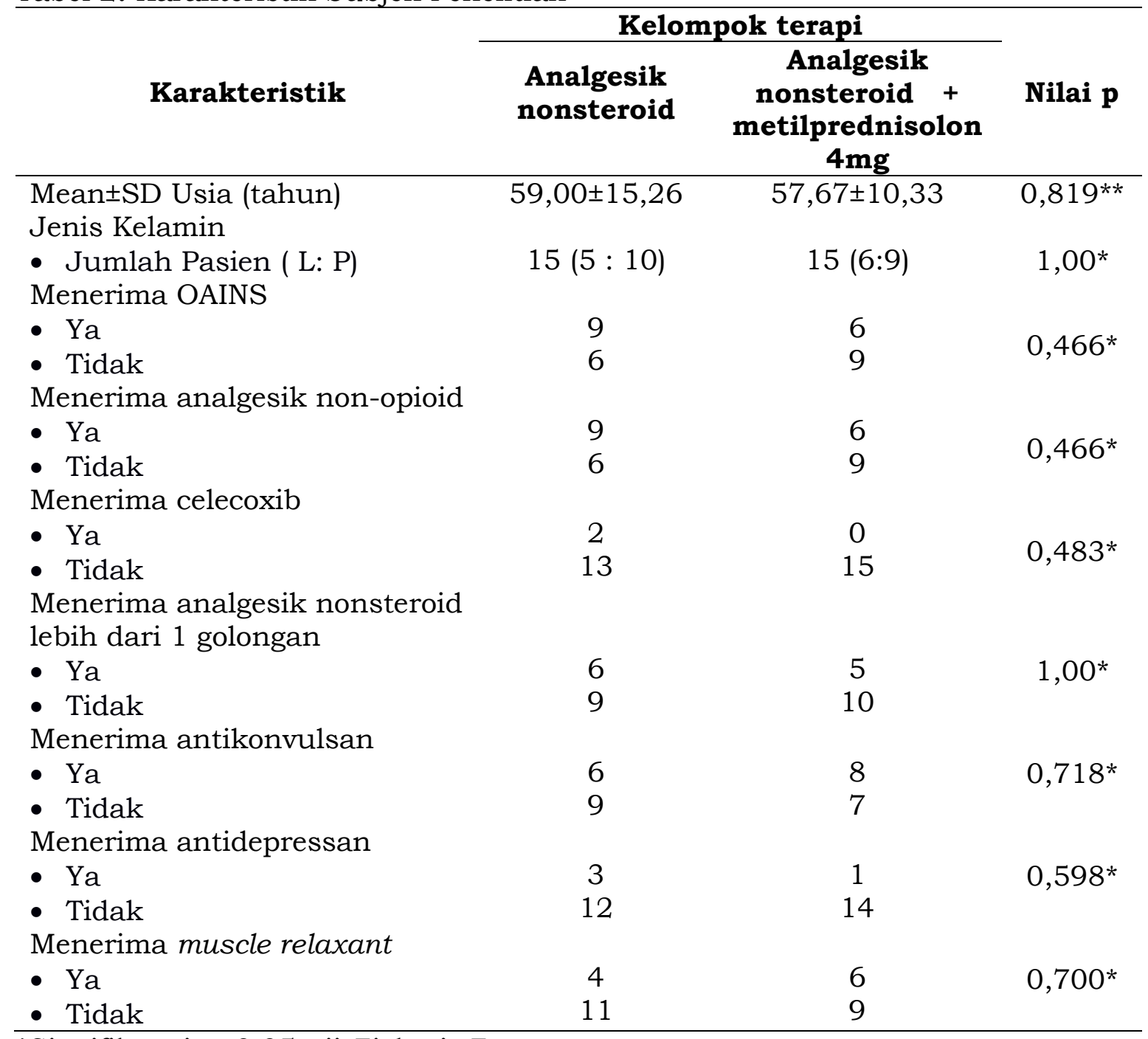

*Signifikansi p<0,05 uji Fisher's Exact

**Signifikansi p<0,05 uji Mann-Whitney $U$

Tabel 2 menunujukkan perbandingan jenis kelamin pada kelompok analgesik nonsteroid dan analgesik nonsteroid dengan metilprednisolon $4 \mathrm{mg}$ adalah 5 : 10 dan 6:9 dengan nilai $\mathrm{p}$ yang diperoleh dengan uji Fisher's Exact adalah $(p=1,00)$. Terapi lain yang diterima pasien selain golongan analgesik seperti antidepressan, muscle relaxant, antikonvulsan dan atau menerima lebih dari sama dengan 2 jenis analgesik lain dianalisis dengan uji Fisher's Exact dan diperoleh nilai $\mathrm{p}>0,05$. 
Hubungan Kelompok Terapi terhadap Penurunana nilai VAS, Outcome Terapi dan Efek Samping Aktual

Analisis ini digunakan untuk menentukan ada tidaknya hubungan antara jenis kelompok terapi pada NPB akut dengan outcome terapi (tabel 5) dan efek samping aktual yang terjadi. Data nilai VAS pada 2 kelompok besar dianalisis dengan uji Mann Whitney $U$ dan data nilai VAS pada 3 kelompok kecil diuji dengan uji Kruskal-Wallis dengan batas nilai signifikansi $\mathrm{p}<0,05$. Data nominal outcome terapi dan efek samping aktual dianalisis dengan uji Fisher's Exact dengan batas nilai signifikansi $\mathrm{p}<0,05$.

Tiga dari 15 pasien (20\%) pada kelompok analgesik nonsteroid dengan tambahan metilprednisolon cenderung merasakan tidak adanya pengurangan nyeri saat beraktivitas dan 4 dari 15 pasien $(26,67 \%)$ pada kelompok tersebut juga mengeluhkan nyeri saat atau menjelang tidur setelah menerima terapi, namun analisis data dengan uji Fisher's Exact diperoleh nilai p >0,05 untuk kedua outcome terapi (tabel 4).
Kejadian efek samping pada kedua kelompok tidak berbeda atau sama. Satu dari 15 (6,7\%) pasien pada kedual kelompok mengalami kejadian efek samping gastrointestinal, sedangkan untuk kejadian efek samping insomnia dan peningkatan nafsu makan tidak ditemukan pada kedua kelompok.

Hasil analisis hubungan terapi dengan nilai VAS sebelum dan sesudah terapi pada kedua kelompok dengan uji Wilcoxon signed rank diperoleh nilai $p<0,05$. Hasil tersebut menunjukkan bahwa terdapat perbedaan rata-rata nilai VAS sebelum dan setelah terapi atau pemberian terapi pada kedua kelompok mempengaruhi intensitas nyeri yang diukur dengan VAS.

Selisih nilai VAS untuk pemberian regimen dosis metilprednisolon yang berbeda dianalisis dengan uji Kruskal-Wallis dan diperoleh nilai $\mathrm{p}=0,792$ (tabel 6) dimana tidak ada pengaruh regimen dosis metilprednisolon yang ditambahkan pada terapi NPB akut terhadap selisih nilai VAS sebelum dan sesudah terapi.

Tabel 3. Penurunan Nilai VAS

\begin{tabular}{cccc}
\multirow{2}{*}{ Kelompok Terapi } & \multicolumn{2}{c}{ Rata-rata \pm SD nilai VAS } & \multirow{2}{*}{ Nilai p* } \\
\cline { 2 - 3 } & Sebelum Terapi & Sesudah terapi & \\
\hline Analgesik nonsteroid & $5,65 \pm 2,94$ & $3,17 \pm 2,43$ & 0,002 \\
Analgesik nonsteroid & & & \\
+ metilprednisolon 4 & $6,63 \pm 2,43$ & $4,50 \pm 3,17$ & 0,001
\end{tabular}

mg

*Signifikansi $\mathrm{p}<0,05$ uji Wilcoxon signed rank

\section{PEMBAHASAN}

Pada penelitian ini analisis statistik untuk penurunan intensitas nyeri pada kedua kelompok tidak menunjukkan perbedaan yang bermakna. Penambahan metilprednisolon sebagai pereda nyeri dapat menurunkan nyeri pada kelompok pasien NPB akut namun penurunan intenitas tidak lebih besar dibandingkan dengan kelompok NPB akut tanpa tambahahan metilprednisolon. Menurut Friedman, et al, penggunaan metilprednisolon tidak memberikan perbaikan yang signifikan atau berbeda bermakna pada pasien NPB akut dibandingkan dengan pasien NPB akut tanpa metilprednisolon. ${ }^{2}$ 
Intesitas diukur dengan VAS pada hari ke-3 hingga hari ke-14 setelah pasien menerima terapi untuk NPB akut. Hal tersebut didasarkan kepada profil farmakokinetik metilprednisolon yang dikombinasikan dengan obat golongan lain. Profil farmakokinetik dapat mempengaruhi pencapaian efek dan timbulnya efek samping dari metilprednisolon.

Menurut Casazza dan
Evaniew, et al., penggunaan steroid dapat menimbulkan efek samping seperti gangguan gastrointestinal akibat penggunaan golongan steroid dikarenakan mekanisme dari steroid yang menghambat asam arakidonat oleh pospolipase sehingga tidak terbentuk prostaglandin termasuk prostaglandin $1 \quad\left(\mathrm{PGE}_{1}\right)$ dan prostaglandin $2 \quad\left(\mathrm{PGE}_{2}\right)$ yang berfungsi sebagai pelindung gastrointestinal.11,12 Pada penelitian Friedman, tidak ada laporan mengenai gangguan gastrointestinal pada kelompok dengan tambahan metilprednisolon. ${ }^{2}$ Hasil pada penelitian ini menunjukkan pada kedua kelompok terapi tidak terdapat perbedaan terhadap kejadian gangguan gastrointestinal setelah menerima terapi $(p=1,00)$. Gangguan nafsu makan juga dapat terjadi pada penggunaan steroid. Steroid dapat mempengaruhi Gonadal Steroid Hormone (GSH) untuk menstimulasi nafsu makan.13 Pada penelitian ini tidak terdapat kejadian peningkatan nafsu makan pada kelompok terapi analgesik dengan tambahan metilprednisolon $4 \mathrm{mg}$ ataupun kelompok analgesik tanpa penambahan metilprednisolon $4 \mathrm{mg}$. Obat-obatan golongan steroid dapat mensupresi slow-wave sleep (SWS) sehingga seseorang akan sulit untuk tidur atau insomnia. ${ }^{14}$

Efek samping jangka panjang dari metilprednisolon seperti deposit lemak pada jaringan lemak pipi dan lengan, imunosupresif, thromboemboli, pendarahan gastrointenstinal, osteoporosis, DM, dan hipertensi tidak berpontesi untuk terjadi karena penggunaan metilprednisolon pada terapi NPB akut hanya diresepkan untuk 8-10 hari dengan dosis 4-8 mg/hari. Penghentian metilprednisolon untuk penggunaan kurang dari 7 hari tidak memerlukan tapering off karena tidak terjadi supresi hipotalamus-pituitariadrenal (HPA) dan kadar kostisol dalam darah akan kembali normal dalam waktu 5-7 hari. ${ }^{8}$

Keterbatasan utama dari penelitian ini adalah kurangnya waktu melakukan pengamatan. Walaupun jumlah sampel yang digunakan tidak besar dan kriteria inklusi yang tidak terlalu ketat namun waktu penelitian yang terbatas mempengaruhi jumlah sampel.

Tabel 4. Perbandingan Nilai VAS pada 2 Kelompok terapi

\begin{tabular}{lccc}
\hline & $\begin{array}{c}\text { Analgesik } \\
\text { Nonsteroid }\end{array}$ & $\begin{array}{c}\text { Analgesik Nonsteroid } \\
+ \text { Metiprednisolon 4mg }\end{array}$ & Nilai p* \\
\hline $\begin{array}{l}\text { Mean } \pm \text { SD VAS sebelum } \\
\text { terapi }\end{array}$ & $5,65 \pm 2,94$ & $6,6 \pm 2,43$ & 0,519 \\
$\begin{array}{l}\text { Mean } \pm \text { SD VAS sesudah } \\
\text { terapi }\end{array}$ & $3,17 \pm 2,43$ & $4,50 \pm 3,17$ & 0,271 \\
Mean \pm SD Selisih VAS & $2,75 \pm 1,94$ & $2,12 \pm 1,88$ & 0,253 \\
\hline
\end{tabular}

*Signifikansi p<0,05 uji Mann-Whitney $U$ 
Tabel 5. Outcome Terapi dengan tambahan metilprednisolon 4 mg pada terapi NPB Akut

\begin{tabular}{|c|c|c|c|c|c|}
\hline \multirow{3}{*}{ Outcome } & \multirow{2}{*}{\multicolumn{2}{|c|}{$\begin{array}{c}\text { Analgesik } \\
\text { Nonsteroid }\end{array}$}} & \multirow{2}{*}{\multicolumn{2}{|c|}{$\begin{array}{c}\text { Analgesik } \\
\text { Nonsteroid + } \\
\text { metilprednisolon } \\
4 \mathrm{mg} \\
\end{array}$}} & \multirow{3}{*}{ Nilai p } \\
\hline & & & & & \\
\hline & $\mathbf{n}$ & $\%$ & $\mathbf{n}$ & $\%$ & \\
\hline \multirow{4}{*}{\multicolumn{6}{|c|}{$\begin{array}{l}\text { Mengurangi nyeri saat } \\
\text { beraktivitas } \\
\text { - Ya } \\
\text { - Tidak } \\
\text { Mengurangi nyeri menjelang/saat } \\
\text { beristirahat (tidur) }\end{array}$}} \\
\hline & & & & & \\
\hline & & & & & \\
\hline & & & & & \\
\hline - Ya & 14 & 93,3 & 11 & 73,3 & 0,330 \\
\hline - Tidak & 1 & 6,7 & 4 & 26,7 & \\
\hline
\end{tabular}

*Signifikansi p<0,05 uji Mann-Whitney $U$

Tabel 6. Perbandingan terapi NPB Akut dengan Analgesik Nonsteroid, Analgesik Nonsteroid + metilprednisolon $4 \mathrm{mg}$ 1x/hari dan Analgesik Nonsteroid + metilprednisolon $4 \mathrm{mg} 2 \mathrm{x} /$ hari.

\begin{tabular}{lcccc}
\hline & $\begin{array}{c}\text { Analgesik } \\
\text { Nonsteroid }\end{array}$ & $\begin{array}{c}\text { Analgesik } \\
\text { Nonsteroid }+ \\
\text { metiprednisolon } \\
\text { 4mg 1x/hari }\end{array}$ & $\begin{array}{c}\text { Analgesik } \\
\text { Nonsteroid }+ \\
\text { metiprednisolon } \\
\text { 4mg 2x/hari }\end{array}$ & Nilai p \\
\hline $\begin{array}{l}\text { Mean } \pm \text { SD } \\
\text { Selisih VAS }\end{array}$ & $2,75 \pm 1,88$ & $1,81 \pm 1,35$ & $1,96 \pm 2,30$ & 0,792 \\
\hline
\end{tabular}

*Signifikansi $\mathrm{p}<0,05$ uji Kruskal-Wallis

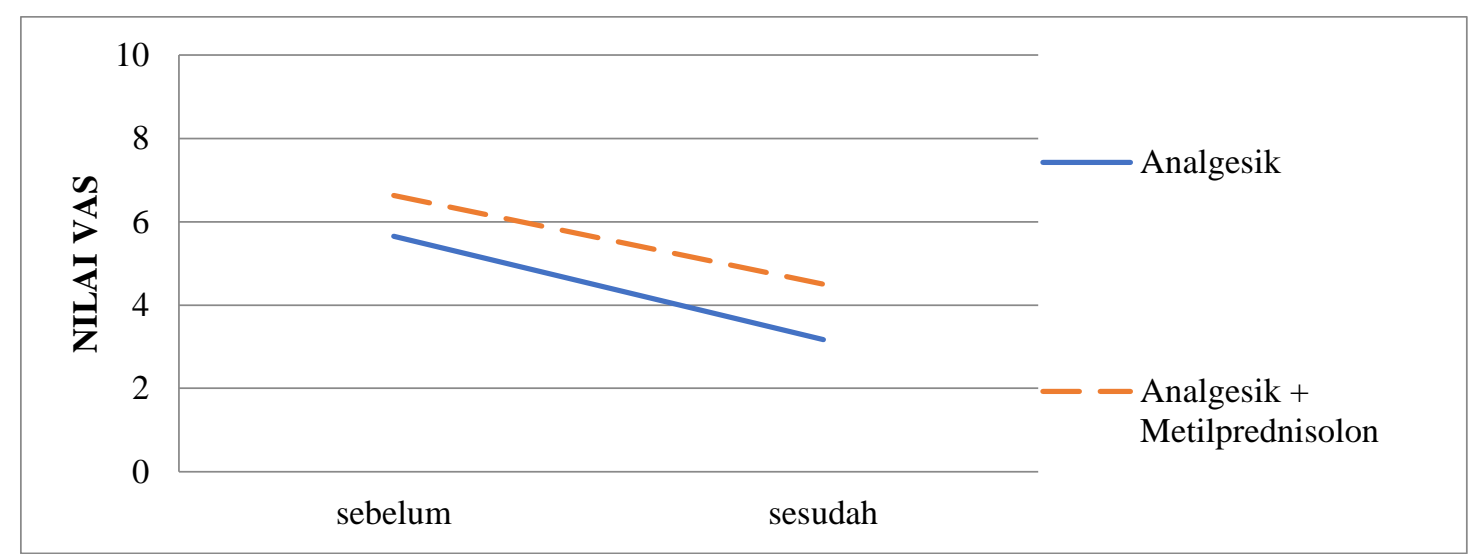

Gambar 1. Grafik Rata-rata Nilai VAS Sebelum dan Sesudah Terapi

\section{KESIMPULAN}

Ada penurunan nilai VAS pada penambahan metilprednisolon pada terapi NPB akut di instalasi rawat jalan rumah sakit Bethesda Yogyakarta. Penurunan nilai VAS dan kejadian efek samping pada penggunaan metilprednisolon berbeda tidak bermakna dengan terapi NPB akut tanpa metilprednisolon.

\section{DAFTAR PUSTAKA}

1. Patrianingrum, M., Oktaliansah, E., Surahman, E., Prevalensi dan Faktor Risiko Nyeri Punggung Bawah di Lingkungan Kerja Anestesiologi Rumah Sakit Dr. 
Hasan Sadikin Bandung, Jurnal Anestesi Perioperatif, Vol. 3, 2015

2. Friedman, BW., Esses, D., Solorzano, C., Choi, HK., Cole, M., Davitt, Bijur, et al, A Randomized Placebo Controlled Trial of Single Dose IM Corticosteroid for Radicular Low Back Pain, NIH Public Access, 2008

3. Piccoliori, G., Engl A., Gatterer, D., Sessa, E., Schimetten, J.I.D., Abholz, H.H., Management of low back pain in general practice - is it of acceptable quality: anobservational study among 25 general practices in South Tyrol (Italy), BMC Family Practice, $14: 148,2013$

4. Docking, RE., Fleming, J., Brayne C., Zhao J., Macfarlane GJ., Jones GT., Epidemiology of Back Pain in Older Adults : Prevalence and Risk Factors for Back Pain Onset, British Society for Rheumatology, Oxford University Press, 2011

5. Fauci AS, Kasper DL, Longo DL, et al., Back and Neck Pain. Harrison's Principles of Internal Medicine. 17th Edition. McGrawHill, New York, 2008

6. Gupta, P., Bhatia, V., Corticosteroid Physiology and Priciples Therapy, Indian Jurnal Pediatric, vol.75, 2008

7. Royal Pharmaceutical Society, British National Formulary 69, Pharmaceutical Press, United Kingdom, 2015.

8. Prashar, DV., Pahwa, D., Kalia, V., Jindal, G., Kaur, R, A
Comparative Evaluation of The Effect of Diclofenac Sodium with or without Per-Orally Administrated

Methylprednisolone on The Sequelae of Impacted Mandibular Third Molar Removal: A cohort randomized double blind clinical trial, Indian Journal of Dentistry, vol.7, 2016

9. Finckh A, et al., Short-Term Efficacy of Intravenous Pulse Glucocorticoids in Acute Discogenic Sciatica. A randomized controlled trial. Spine., 2006

10. Purba, JS., Rumawas AM., Nyeri Punggung : Studi Epidemiologi, Patofisiologi dan Penanggulangan, Berkala Neurosains, Vol. 7, 2006.

11. Casazza B.A, Diagnosis and Treatment of Acute Low Back Pain, Indian Journal of Clinical Practice, Vol. 23, 2012

12. Evaniew N., Noonan V.K., Fallah N., Kwon B.K., Rivers C.S., Ahn H., et al, Methylprednisolone for the Treatment of Patients with Acute Spinal Cord Injuries: A Propensity Score-Matched Cohort Study from a Canadian Multi Center Spinal Cord Injury Registry, Journal Of Neurotrauma, 2015

13. Asarian, L., Geary, N., Modulation of Appetite by Gonadal Steroid Hormon, The Royal Society, 2006

14. Malangu, N., Drug Inducing Insomnia as an Adverse Effect, dalam: Can't Sleep? Issue of Being an Insomniac, South Africa, In Tech, 2012 